\title{
ANÁLISE DE CUSTO DE PRODUÇÃo E LUCRATIVIDADE DE BANANEIRA 'NANICÃO JANGADA' SOB DUAS DENSIDADES DE CULTIVO EM ILHA SOLTEIRA-SP ${ }^{1}$
}

\author{
PATRICIA DA COSTA ZONETTI ${ }^{2}$, MARIA APARECIDA ANSELMO TARSITANO ${ }^{3}$, PEDRO CÉSAR DOS \\ SANTOS $^{3}$, SIMÃO CORRÊA E SILVA ${ }^{2}$, RICARDO ALESSANDRO PETINARI ${ }^{2}$
}

\begin{abstract}
RESUMO - Em fruticultura, existe hoje uma grande tendência de aumento da densidade de cultivo, procurando com isso uma maior produção por área. Pretendeu-se, neste trabalho, desenvolvido em Ilha Solteira-SP, estimar e analisar comparativamente o custo de produção e a lucratividade de bananeira- 'Nanicão Jangada', sob duas densidades de cultivo: 1666 plantas (3,0mx2,0m) e 2500 plantas (2,0mx2,0m). Para o cálculo do custo, utilizou-se a estrutura do custo total de produção (CTP). Considerando os dois ciclos produtivos do bananal, o espaçamento de plantio mais adensado (com maior número de plantas por área) apresentou resultados econômicos mais satisfatórios que os obtidos para o cultivo menos adensado. A cultivar 'Nanicão Jangada' é uma alternativa de cultivo viável para a região de Ilha Solteira-SP.
\end{abstract}

Termos para indexação: banana, adensamento, custo de produção, lucratividade.

\section{ANALYSIS OF PRODUCTION COST AND PROFITBILITY OF BANANA 'NANICÃO JANGADA' IN TWO CROP DENSITIES IN ILHA SOLTEIRA/SP}

\begin{abstract}
In fruit growing, there is a large tendency to increase the plant density, attempting to increase productivity per area. The objetive of this study, elaborated in Ilha Solteira-SP, was to value and to analyse comparatively the production cost and the profitbility of the banana type 'Nanicão Jangada' using two growing densities: 1666 plants (3.0mx2.0m) and 2500 plants $(2.0 \mathrm{mx} 2.0 \mathrm{~m})$. For the cost calculation, the method of total producion cost (TPC) was used. Taking into consideration the two productive cycles of the banana, the higher density (with the larger number of plants per area) presented better economical results than obtained with lower density. The growing of the 'Nanicão Jangada' is a viable cultivation alternative for the region of Ilha Solteira-SP.
\end{abstract}

Index terms: banana, higher density, production costs, profitbility.

\section{INTRODUÇÃO}

A banana, hoje, é a fruta mais produzida e a mais consumida no mundo. A produção mundial de bananas é de aproximadamente 58,69 milhões de toneladas (FAO, 2001). O Brasil encontra-se como o segundo maior produtor, perdendo somente para a Índia, cuja produção é aproximadamente duas vezes maior. A produção brasileira chegou a 6,3 milhões de toneladas em 2000 (FAO, 2001).

No Brasil, a região Sudeste tem-se mostrado a região com maior produção de banana, em torno de 2,2 milhões de toneladas, o que representa $33,25 \%$ da produção brasileira, e o Estado de São Paulo vem contribuindo com 1,1 milhão de toneladas, em média 49,5\% da produção desta região (Nehmi et al., 2000). A bananicultura paulista concentra-se nas regiões do Vale do Ribeira e Litoral Sul, onde se situam 13 municípios com maiores áreas plantadas, representando $77 \%$ do total de produção do Estado (Pino et al., 2000).

O espaçamento utilizado no bananal influi diretamente no ciclo vegetativo e, conseqüentemente, no ciclo de produção. No geral, maiores densidades implicam maiores ciclos (Moreira, 1987; Licthemberg et al., 1988; Lichtemberg et al., 1997; Rangel et al.,
1998; Kluge et al., 1999).

A escolha do espaçamento é um aspecto que vem sendo muito discutido na cultura da bananeira. Vários fatores podem influenciar na escolha da densidade de plantio, como: fatores climáticos, disponibilidade de mão-de-obra, tipo de cultivar, topografia, fertilidade de solo, entre outros (Soto Ballestero \& Sancho, 1992; Lichtemberg et al., 1997). Segundo Lichtemberg (1984), o espaçamento ideal deve ser aquele em que as plantas conseguem maior produção por área, sem que haja redução do peso do cacho.

Souto et al.(1997) alertam que o espaçamento não pode ser pequeno demais, a ponto de promover o estiolamento da planta e dificultar a circulação de ar, e não pode ser muito grande, a ponto de tornar favorável o aparecimento de muitas espécies daninhas.

A variedade Nanicão Jangada é um mutante originado de um Nanicão coletado em Eldorado Paulista (Moreira, 1999). É uma planta de porte médio, com 2,29 a 3,30 metros de altura, apresentando um pseudocaule bem rigoroso (Manica, 1998). Segundo Moreira (1999), o rabo do cacho é quase $100 \%$ limpo de restos florais e bem reto, sendo a distribuição das pencas bem uniforme e regular, e o cacho pode apresentar peso de até $40 \mathrm{Kg}$.

1 (Trabalho 194/2001). Recebido: 27/11/2001. Aceito para publicação: 20/06/2002.

2 Alunos do curso de pós-graduação em Agronomia - Área de concentração Produção Vegetal - FEIS/UNESP

3 Prof. Dr. Depto. de Fitotecnia, Tecnologia de Alimentos e Sócio-Economia -FEIS/UNESP - Av. Brasil, 56 - Caixa postal 31- CEP 15385.000-

Ilha Solteira /SP telefone: (OXX) 18-3743.11.44.* zonettipat@bol.com.br / santospc@agr.feis.unesp.br, telefone (0XX) 14-541.12.59

Rev. Bras. Frutic., Jaboticabal - SP, v. 24, n. 2, p. 406-410, agosto 2002 
A Coordenadoria de Assistência Técnica Integral (Cati, 2001), orienta que, no Estado de São Paulo, bananais da cultivar Nanicão produza entre 30 e 50t/há, dependendo das condições de manejo da cultura durante seu desenvolvimento. Segundo Alves (2001), a produtividade destes pomares no Estado de São Paulo, sob condições de irrigação, pode atingir $60 \mathrm{t} / \mathrm{ha} /$ ciclo.

Face ao crescimento de plantios na região de Ilha Solteira, torna-se importante um estudo do comportamento produtivo da variedade Nanicão Jangada em diferentes densidades de cultivo, para que possa ser indicado um espaçamento onde ocorra maior produtividade, sem prejudicar a qualidade do fruto e que seja viável economicamente para o produtor.

Desta forma, dada a importância de se estudar economicamente diferentes densidades de cultivo, pretende-se, neste trabalho, analisar comparativamente os custos e a lucratividade da bananeira- 'Nanicão Jangada', sob duas densidades de cultivo em Ilha Solteira, região Noroeste do Estado de São Paulo.

\section{MATERIAL E MÉTODOS}

\section{1 - Fonte de dados e caracterização do local}

Os dados foram obtidos no setor "Pomar" da Fazenda de Ensino e Pesquisa da Faculdade de Engenharia - UNESP, Câmpus de Ilha Solteira, situada na latitude $20^{\circ} 22^{\prime} \mathrm{W}$, longitude $51^{\circ} 22^{\prime} \mathrm{W}$ e altitude de 330 metros, no município de Ilha Solteira, região Noroeste do Estado de São Paulo.

O solo predominante do local foi classificado como Argiloso Vermelho-Escuro, Tb, Eutrófico, Abrúptico, A Chernozêmico, Textura Média/Argilosa (EMBRAPA, 1999). O clima apresenta-se como subúmido, com pouca deficiência hídrica, megatérmico e com calor bem distribuído durante o ano, com estiagem no inverno, média anual de temperatura em torno de $24,1^{\circ} \mathrm{C}$ e precipitação anual de $1400 \mathrm{~mm}$.

\section{2 - Caracterização do sistema de produção}

\subsection{Aquisição de mudas}

As mudas da área em estudo foram obtidas pela técnica de micropropagação "in vitro".

\subsection{Preparo do solo}

Como para a maior parte dos diferentes sistemas de produção, o solo foi preparado por uma aração, seguida de uma gradagem.

\subsection{Plantio}

O plantio foi realizado no dia 22 de dezembro de 1988. Inicialmente, foi realizada uma sulcagem, as mudas foram selecionadas e distribuídas ao longo da sulcagem, foi realizado revolvimento do solo com cloreto de potássio, e procedeu-se o plantio manualmente, no espaçamento $3 \mathrm{mx} 2 \mathrm{~m}$ e $2 \mathrm{mx} 2 \mathrm{~m}$.

\subsection{Tratos culturais}

A adubação de formação constou de $60 \mathrm{~g}$ de sulfato de amônia, $30 \mathrm{~g}$ de cloreto de potássio, $135 \mathrm{~g}$ de micronutrientes e 8,3 litros de esterco de galinha por planta.

Foram realizadas duas pulverizações no primeiro ano de produção, e três no segundo ano, conforme a necessidade no decorrer do desenvolvimento da cultura.

Foi aplicado herbicida duas vezes ao ano, nos dois anos de produção, e o escoramento foi realizado conforme a necessidade no campo.
Os desbastes foram realizados de 4 em 4 meses, deixando perfilhos no esquema de planta mãe-filha-neta. Após o corte do pseudocaule, utilizou-se uma ferramenta denominada lurdinha para a morte do ápice meristemático.

A adubação de produção foi realizada duas vezes no primeiro ano de produção e três vezes no segundo ano (de 4 em 4 meses), sendo $350 \mathrm{~g}$ de sulfato de amônia, $50 \mathrm{~g}$ de supersimples e $200 \mathrm{~g}$ de cloreto de potássio por planta.

A irrigação foi realizada por gotejamento, com fitas gotejadoras em cada linha de plantio.

\subsection{Colheita}

Os cachos foram colhidos manualmente, de acordo com o método subjetivo citado por Chitarra \& Chitarra (1994), de desaparecimento da angulosidade dos frutos.

\section{3 - Estrutura e cálculo do custo de produção}

Foi utilizada para o cálculo do custo de produção a estrutura do custo total de produção (CTP), composto pelo custo operacional efetivo (COE), custo operacional total (COT), remuneração da terra e remuneração do capital.

O custo operacional efetivo (COE) foi obtido pela soma das despesas com operações mecanizadas, operações manuais e insumos. Somando os valores com os juros de custeio, outras despesas e as depreciações, obtém-se o Custo Operacional Total (COT) e, finalmente, acrescentando-se ao COT as remunerações do capital e da terra, tem-se o Custo Total de Produção (CTP).

- Operações mecanizadas: no custo horário de máquinas, foram considerados os gastos com combustíveis, reparos e manutenção, óleo lubrificante, garagem e tratorista. Para as despesas com reparos e manutenção dos implementos, foi considerada uma taxa que variou de 5 a $10 \%$ sobre o valor do equipamento novo.

- Operações manuais: foi levantada a quantidade de mão-deobra nas diversas atividades da cultura, assim, obtido o número de homens/dia (HD) para executá-la. Para mão-de-obra comum, foi estabelecida a diária de $\mathrm{R} \$ 12,00$, valor referente ao mês de dezembro de 2000.

- Insumos: os preços médios foram coletados na região, em dezembro de 2000, e multiplicados pelas quantidades dos insumos utilizado.

- Juros de custeio: foi considerada a taxa de 5,75\%a.a. (Juros de custeio PRONAF) sobre a metade das despesas com operações e insumos.

- A depreciação dos bens fixos (irrigação, pomar, e máquinas e equipamentos), ou seja, os que prestam serviços por mais de um ciclo produtivo, foi calculada utilizando-se o método linear.

- Para a remuneração do capital investido, foi considerada uma taxa de 6\%a.a. sobre o capital médio empatado na atividade, e para a remuneração da terra, foi considerado o valor do arrendamento da terra na região (valor de $\mathrm{R} \$ 80,00 / \mathrm{ano} / \mathrm{ha}$, referente ao mês de dezembro de 2000).

\section{Indicadores de rentabilidade}

Para calcular a lucratividade da cultura da bananeira em Ilha Solteira, foi considerado o preço médio recebido pelo produtor de $\mathrm{R} \$$ 0,30/kg (referente ao ano de 2000). Foram estimados os seguintes indicadores: receita bruta, como produto da produção pelo preço recebido pelo produtor; a receita líquida, pela 
diferença entre receita bruta e custos de produção; e os índices de lucratividade dados, pela receita líquida divididos pela receita bruta (em porcentagem).

Os preços médios foram coletados na região, em dezembro de 2000, e apresentados em reais $(\mathrm{R} \$$ ) e também convertidos para dólar (US\$), utilizando-se da taxa de câmbio do dólar comercial de $\mathrm{R} \$ 1,95$.

\section{RESULTADOS E DISCUSSÃO}

O custo de implantação e produção estimado para a cultura da bananeira, em duas densidades de plantio, pode ser verificado nas Tabelas 01 e 02 . O custo operacional total (COT) na implantação do pomar foi maior para o cultivo adensado, com $\mathrm{R} \$ 4.495,19$, possivelmente, devido ao maior número de mudas por área, maior quantidade de insumos gastos e maior quantidade de mão-de-obra no pomar.

Nos dois anos de produção, o custo total (CTP) foi de $\mathrm{R} \$ 6.190,67$ e $\mathrm{R} \$ 6.687,22$, respectivamente, para o cultivo mais denso e R \$4.597,85 e R \$5.122,58, respectivamente, para o cultivo menos denso.

A produtividade dos cachos despencados estimada por área, no primeiro e segundo ciclos produtivos foram, respectivamente, de 64,98t/ha e 54,30t/ha no cultivo mais denso e de 41,08t/ ha e 35,50t/ha no cultivo menos denso. Sandrini et al. (1991), trabalhando com a cultivar Nanicão sem irrigação, no Mato Grosso do Sul, obtiveram uma produtividade estimada de $33,54 \mathrm{t} / \mathrm{ha}$ no espaçamento 3,0mx2,0m e 50,23t/ha no espaçamento 2,0mx2,0m. Scarpare Filho \& Kluge (2001), com a mesma cultivar, no espaçamento de 2,0mx3,0m, estimaram uma produtividade de 45,38t/ha em bananal localizado em Piracicaba-SP, sem irrigação.

Os valores de produtividade relativamente altos, encontrados neste trabalho, comparados com a literatura, podem estar associados às condições edafoclimáticas do local do experimento e principalmente à irrigação. Moreira (1999) afirma que a irrigação feita de modo a suprir efetivamente as necessidades hidricas de plantas sadias pode levar a um aumento na produtividade por ano em até $100 \%$.

O valor de mercado considerado para a comercialização foi de $\mathrm{R} \$ 0,30$, resultando em uma receita bruta $(\mathrm{RB})$ de $\mathrm{R} \$ 19.494,00$ e $\mathrm{R} \$ 16.290,00$, no primeiro e segundo anos de produção para o cultivo mais adensado e de $\mathrm{R} \$ 12.324,00$ e $\mathrm{R} \$ 10.650,00$ no primeiro e segundo anos de produção para o cultivo menos adensado. Os valores de receita líquida foram maiores para o cultivo adensado, com $\mathrm{R} \$ 13.303,33$ e 9.602,78, nos dois anos de produção, resultando num total de R $\$ 22.906,11$, e para o cultivo menos adensado, o total de receita líquida foi de $\mathrm{R} \$ 12.802,03$; isto significa, para o cultivo mais adensado, uma receita $68,46 \%$ maior que o obtido pelo cultivo menos adensado (Tabela 03). Os índices de lucratividade mostraram-se altos, tanto para o cultivo mais adensado com para o menos adensado, com uma média de 64,00\% para o mais adensado e 55,70 \% para o menos adensado (Tabela 03).

TABELA 1 -Estimativa do custo de formação e produção por hectare de bananeira-'Nanicão Jangada' na densidade de 2500 plantas/ ha (espaçamento 2,0mx2,0m) em Ilha Solteira-SP, dezembro de 2000.

\begin{tabular}{|c|c|c|c|c|c|c|}
\hline \multirow{3}{*}{ Operações } & \multicolumn{3}{|c|}{ Valor em R\$ } & \multicolumn{3}{|c|}{ Valor em US\$ } \\
\hline & Formação & Produção & & Formação & Produção & \\
\hline & & $1^{\circ}$ ciclo & $2^{\circ}$ ciclo & & $1^{\circ}$ ciclo & $2^{\circ}$ ciclo \\
\hline Operações mecanizadas & 562,30 & 502,10 & 508,28 & 288,36 & 257,49 & 260,66 \\
\hline Operações manuais & 237,00 & $1.146,00$ & $1.272,00$ & 121,54 & 587,69 & 652,31 \\
\hline Insumos & $3.570,28$ & $1.911,38$ & $2.504,27$ & $1.830,91$ & 980,19 & $1.284,24$ \\
\hline Custo operacional efetivo & $4.369,57$ & $3.559,48$ & $4.285,25$ & $2.240,80$ & $1.825,38$ & $2.197,56$ \\
\hline Juros de custeio & 125,62 & 102,33 & 123,20 & 64,42 & 52,48 & 63,18 \\
\hline Depreciações & & $2.270,88$ & $2.278,67$ & & $1.164,55$ & $1.168,55$ \\
\hline Custo Operacional Total & $4.495,19$ & $5.932,69$ & $6.687,22$ & $2.305,23$ & $3.042,40$ & $3.429,34$ \\
\hline Remuneração da Terra & & 80,00 & 80,00 & & 41,03 & 41,03 \\
\hline Remuneração do Capital & & 177,98 & 200,62 & & 91,27 & 102,88 \\
\hline Custo Total & $4.495,19$ & $6.190,67$ & $6.687,22$ & $2.305,23$ & $3.174,70$ & $3.429,34$ \\
\hline Custo/cacho & & 0.08 & 0.10 & & 0.041 & 0.052 \\
\hline
\end{tabular}

Valor do dólar comercial em 20-12-2000: R \$1,95

Rev. Bras. Frutic., Jaboticabal - SP, v. 24, n. 2, p. 406-410, agosto 2002 
TABELA 2 - Estimativa do custo de formação e produção por hectare de bananeira-'Nanicão Jangada' na densidade de 1666 plantas/ ha (espaçamento 2,0mx3,0m) em Ilha Solteira-SP, dezembro de 2000.

\begin{tabular}{|c|c|c|c|c|c|c|}
\hline \multirow{3}{*}{ Operações } & \multirow{2}{*}{\multicolumn{3}{|c|}{$\begin{array}{c}\text { Valor em R\$ } \\
\text { Produção }\end{array}$}} & \multicolumn{3}{|c|}{ Valor em US\$ } \\
\hline & & & & \multirow[t]{2}{*}{ Formação } & \multicolumn{2}{|c|}{ Produção } \\
\hline & & $1^{\circ}$ ciclo & $2^{\circ}$ ciclo & & $1^{\circ}$ ciclo & $2^{\circ}$ ciclo \\
\hline Operações mecanizadas & 519,51 & 465,49 & 465,49 & 266,42 & 238,71 & 238,71 \\
\hline Operações manuais & 165,60 & 914,40 & 978,00 & 84,92 & 468,92 & 501,54 \\
\hline Insumos & $2.396,92$ & $1.491,62$ & $1.930,34$ & $1.229,19$ & 764,93 & 989,92 \\
\hline Custo operacional efetivo & $3.082,03$ & $2.871,51$ & $3.373,83$ & $1.580,53$ & $1.472,57$ & $1.730,17$ \\
\hline Juros de custeio & 88,61 & 82,56 & 97,00 & 45,44 & 42,34 & 49,74 \\
\hline Depreciações & & $1.643,78$ & $1.651,67$ & & 842,96 & 847,01 \\
\hline Custo Operacional Total & $3.170,64$ & $4.597,85$ & $5.122,50$ & $1.625,97$ & $2.357,87$ & $2.626,92$ \\
\hline Remuneração da Terra & & 80,00 & 80,00 & & 41,03 & 41,03 \\
\hline Remuneração do Capital & & 137,94 & 153,68 & & 70,74 & 78,81 \\
\hline Custo Total & $3.170,64$ & 4815,79 & 5356,18 & $1.625,97$ & $2.469,63$ & $2.746,76$ \\
\hline Custo/cacho & & 0.09 & 0.12 & & 0.046 & 0.061 \\
\hline
\end{tabular}

Valor do dólar comercial em 20-12-2000: R \$1,95

TABELA 3 - Comparação dos Indicadores de lucratividade obtidos em bananal nas densidades de 2500 plantas/ha e 1666 plantas/ha (2,0mx2,0m e 2,0mx3,0m) em Ilha Solteira, dezembro de 2000.

\begin{tabular}{|c|c|c|c|c|}
\hline \multirow[b]{2}{*}{ Custo Total } & \multicolumn{2}{|c|}{ Densidade de $2500 \mathrm{pl} / \mathrm{ha}$} & \multicolumn{2}{|c|}{ Densidade de $1666 \mathrm{pl} / \mathrm{ha}$} \\
\hline & $\mathbf{R} \$$ & US \$ & $\mathbf{R} \$$ & US \$ \\
\hline primeiro ciclo & $6.190,67$ & $3.174,70$ & $4.815,79$ & $2.469,64$ \\
\hline segundo ciclo & $6.687,22$ & $3.429,34$ & $5.356,18$ & $2.746,76$ \\
\hline Total & $12.877,89$ & $6.604,05$ & 10.171 .91 & $5.216,39$ \\
\hline \multicolumn{5}{|l|}{ Receita Bruta } \\
\hline primeiro ciclo & $19.494,00$ & $9.996,92$ & $12.324,00$ & $6.320,00$ \\
\hline segundo ciclo & $16.290,00$ & $8.353,85$ & $10.650,00$ & $5.461,54$ \\
\hline Total & $35.784,00$ & $18.350,77$ & $22.974,00$ & $11.781,54$ \\
\hline \multicolumn{5}{|c|}{ Receita Líquida } \\
\hline primeiro ciclo & $13.303,33$ & $6.822,22$ & $7.508,21$ & $3.850,36$ \\
\hline segundo ciclo & $9.602,78$ & $4.924,50$ & $5.293,82$ & $2.714,78$ \\
\hline Total & $22.906,11$ & $11.746,72$ & $12.802,03$ & $6.565,14$ \\
\hline \multicolumn{5}{|c|}{ Índice de lucratividade (\%) } \\
\hline primeiro ciclo & 68,20 & 68,20 & 60,90 & 60,90 \\
\hline segundo ciclo & 58,90 & 58,90 & 49,70 & 49,70 \\
\hline Total & 64,00 & 64,00 & 55,70 & 55,70 \\
\hline
\end{tabular}

Valor do dólar comercial em 20-12-2000: R \$1,95

\section{CONCLUSÕES}

1. A cultivar Nanicão Jangada é uma alternativa de cultivo viável para a região de Ilha Solteira-SP. Considerando os dois ciclos produtivos do bananal, o espaçamento de plantio mais adensado (com maior número de plantas por área) apresentou resultados econômicos mais satisfatórios que os obtidos para o cultivo menos adensado.
2. Como limitação, os dados utilizados para análise econômica da banana foram obtidos de um experimento conduzido na FEP da UNESP e, por ser nova na região, principalmente a 'Nanicão', necessita de mais estudos técnicos e econômicos, principalmente voltados para espaçamento, irrigação, pós-colheita (climatização) e na comercialização da fruta.

3. Há potencial para o crescimento da produção e comercialização da banana-'Nanica' ou 'Nanicão' nesta região, especialmente 
para os produtores que procurarem adequar-se às exigências de qualidade.

\section{REFERÊNCIAS BIBLIOGRÁFICAS}

ALVES, S.A.M. Cultura da Banana. Disponível em <http:// www.cursosagricolas.hpg.ig.com.br/cultivares.htm>. Acesso em: 13 ago. 2001.

BANERJEE, N.; DE LANGHE, E. A tissue culture technique for rapid clonal propagation and storage under minimal growth conditions of Musa (Banana and Plantains). Plant Cell Reports, Berlin, v.4, p.351-354, 1985.

CATI. Disponível em: <http://www.estado.estadão.com.br/jornal/suplem>. Acesso em: 13 ago. 2001.

CHITARRA, A.B.; CHITARRA, M.I.F. Pós-colheita de banana. Informe Agropecuário, Belo Horizonte, v17, n.179, p.41-47, 1994.

EMBRAPA. Centro Nacional de Pesquisa de Solos. Sistema Brasileiro de Classificação de Solos.Brasília: Embrapa Produção de Informação; Rio de Janeiro: Embrapa Solos, 1999, 42p.

FAO Production Yearbook - 1990, Rome, v.44, p.169-170, 1991.

FAO Statistical database. capturado em 30 de abril, 2001. Online Disponível na Internet http://www.fao.org .

KLUGE, R.A.; SCARPARE FILHO, J.A.; VICTÓRIA FILHO, R. Densidade e sistema de espaçamento de bananeiras 'Nanicão': duração do ciclo e do período de colheita. Scientia Agricola, Piracicaba, v.56, n.4, p.811-818, 1999.

LICHTEMBERG, L.A. Espaçamento e desbaste para bananeiras. Informativo da Sociedade Brasileira de Fruticultura, v.3, n.3, p. 15-16, 1984.

LICHTEMBERG, L.A. MALBURG, J.L.; HINZ, R.H. Espaçamento e desbaste para a banana 'Enxerto'. In: CONGRESSO BRASILEIRODE FRUTICULTURA, 9., 1988, Campinas. Anais...Campinas: SBF, 1988. v.1, p.161-169.
LICHTEMBERG, L.A. ; HINZ, R.H.; MALBURG, J.L.; STUKER, H. Crescimento e duração dos cinco primeiros ciclos da bananeira Nanicão sob três densidades de plantio. Revista Brasileira de Fruticultura, Cruz das Almas, v.19 n.1, p. 15-23, 1997.

MANICA, I. Bananas: do plantio ao amadurecimento. Porto Alegre: Cinco Continentes, 1998.98p.

MOREIRA, R.S. Banana: Teoria e prática de cultivo. Campinas: Fundação Cargill, 1987, 335p.

MOREIRA, R.S. Banana: Teoria e prática de cultivo. Campinas: Fundação Cargill, 1999. CD-ROM.

NEHMI, I.M.D. et al. (Coord.) Agrianual 2000. Anuário Estatístico da agricultura brasileira. São Paulo: FNP Consultoria \& Comércio. 2000.p.194-98.

PINO, F.A.; SANTOS FRANCISCO, V.L.F.; PEREZ, L.H.; AMARO, A.A.. A cultura da banana no Estado de São Paulo. Informações Econômicas, São Paulo, v.30; n.6, junho de 2000.

RANGEL, A.; PENTEADO, L.A.C.; TONET, R.M. Cultura da banana. Campinas: Coordenadoria de Assistência Técnica Integral - CATI, 1998. 66p (Boletim técnico, 234).

SANDRINI, M. ; CINTRA, F.L.; XIMENES, J.R. Avaliação de Sistemas de Cultivo de Bananeira no Mato Grosso do Sul. Pesquisa Agropecuária Brasileira, Brasília, v.26, n.5, p. 631-635, 1991.

SCARPARE FILHO, J.A.; KLUGE, R.A. Produção da bananeira 'Nanicão' em diferentes densidades de plantas e sistemas de espaçamento. Pesquisa Agropecuária Brasileira, Brasília, v.36, n.1, p.105-113, 2001.

SOTO BALLESTERO, M.; SANCHO, H. Ecología del banana. In: SOTO BALLESTERO, M.S. Bananos: Cultivo y comercialización. Costa Rica: Litografic e Imprenta LIC, 1992 cap.5, p.211-265.

SOUTO, R.F.; RODRIGUES, M.G.V.; ALVARENGA, C.D; SILVA, J.T.A.; MAENO, P.; GONZAGA, V. Sistema de produção para a cultura da banana 'Prata Anã'. Belo Horizonte: EPAMIG, 1997. 34p. (Boletim Técnico, 48). 